\title{
Reformas institucionales y coordinación gubernamental en la política de protección social de Brasil
}

\section{Vilmar E. Faria \\ Doctor en Sociología}

Este trabajo póstumo examina la experiencia brasileña reciente de formulación y ejecución de políticas públicas en el área social con el fin de evaluar las perspectivas de establecer una “autoridad social” que centralice y coordine esas políticas. Describe la compleja estructura brasileña de exclusiones y vulnerabilidades en que se insertan las reformas del área social. Reseña la estrategia de desarrollo social adoptada como parte del Plan Real en 1994, la que busca reestructurar el financiamiento, gastos y beneficios del sistema de protección social para aumentar su eficacia, cobertura e impacto redistributivo. Y analiza la coordinación de las políticas federales para el área social, especialmente en el plano macropolítico e intergubernamental, destacando la creación de cámaras sectoriales y mecanismos de integración de políticas en lugar de estructuras burocráticas de articulación. 


\section{I}

\section{Introducción}

En los últimos quince años, como resultado de desafíos provenientes de diversos sectores y varias crisis, Brasil ha sufrido importantes transformaciones estructurales que han tenido repercusiones significativas en el plano institucional.

Fueron muchos los factores que llevaron a esas alteraciones. Entre ellos cabe mencionar el proceso de redemocratización, que se aceleró a lo largo del decenio de 1980, y los límites estructurales a que llegó la industrialización protegida llevada adelante por el Estado. La situación se agravó por efecto de las transformaciones tecnológicas y la reorganización del capitalismo en el plano internacional; la falencia política, económica y social del llamado "socialismo real", bajo la hegemonía de la Unión Soviética; la crisis del "Estado de bienestar social" de inspiración socialdemócrata y la consiguiente onda de reformas de este sistema; la intensificación de los procesos de globalización, sobre todo en el plano financiero y en el acceso en tiempo real a una corriente mundial de informaciones e imágenes; y la creciente importancia del conocimiento como factor estratégico de la producción.

Como reacción —oportuna o no- a estos inmensos desafíos, el país tuvo que acometer un conjunto significativo de reformas, entre ellas la aprobación de una nueva Constitución en 1988 y su enmienda parcial en 1994; la adopción de varios planes de reajuste económico que culminaron con el exitoso Plan Real implantado en 1994, consolidando así un período de reformas económicas de gran envergadura en materia de estabilización monetaria, ajuste fiscal, apertura de la economía y un ambicioso programa de privatizaciones; la reforma del Estado, y, por último, sin ser por eso menos importantes, las modificaciones institucionales y programáticas de las políticas de protección social.

Entre las principales reformas figuran, en el plano económico, la liberalización comercial y financie- ra, la modificación del tipo de cambio, la desregulación y la eliminación de las barreras a la inversión extranjera, la privatización y la disciplina fiscal, condiciones necesarias para la futura expansión de la inversión extranjera. En el ámbito social, tuvieron importancia el esfuerzo de concentración del gasto público en los sectores de salud, educación e infraestructura, aunque subsistieron las distorsiones en el sistema previsional. Entre las enseñanzas que deja la experiencia brasileña de reforma figuran el beneficio neto derivado del fin de la inflación y del aumento de los excedentes comerciales, el reajuste del sector financiero con un bajo costo en términos del PIB y la atracción de ahorro externo para reiniciar el ciclo de crecimiento. Como en Brasil no se siguió la secuencia exacta prescrita por los organismos de financiamiento internacional, la reforma implicará para el país nuevos e importantes desafíos en el futuro próximo (Baumann, 1999).

Para comprender el alcance y la significación de la reforma de las políticas de protección social es necesario, por un lado, conocer el contexto estructural más amplio en que se inserta esa reforma — cuyos principales lineamientos acabamos de indicar- $-\mathrm{y}$, por el otro, los antecedentes más importantes de la cuestión social brasileña y del sistema de protección social del país. También es preciso señalar las principales dimensiones del proyecto de desarrollo social que se ha adoptado como parte del Plan Real, y en este proceso, analizar los problemas institucionales asociados con la coordinación de las políticas del gobierno federal para el área social. Por último se impone efectuar un breve balance de los principales resultados obtenidos y de lo mucho que queda aún por hacer en el programa público. En las páginas siguientes procuraremos analizar cada uno de estos aspectos.

(1996-1999), posición desde la cual contribuyó a la formulación del proyecto Alvorada (de combate contra la pobreza en ciudades de menor desarrollo), a la gestación del programa Comunidade Solidaria, y a la incorporación de la Bolsa-Escola a los programas federales. Posteriormente, y hasta su fallecimiento el 27 de noviembre de 2001, se desempeñó como Jefe de la Asesoría Especial del Presidente Fernando Henrique Cardoso. 


\section{II}

\section{Los problemas y las políticas de protección social en el Brasil contemporáneo: una paradoja}

Al iniciarse el decenio de 1990, Brasil se encontraba en una situación social paradójica.

Por un lado, después de al menos 50 años de acelerado crecimiento económico basado en la industrialización sustitutiva y en un papel agresivo del Estado como agente económico, el país había logrado convertirse en una de las más dinámicas y complejas de las sociedades urbano-industriales ubicadas en la periferia del capitalismo y se situaba entre las diez mayores economías del mundo. Contaba con un sector empresarial importante, formado tanto por un amplio empresariado nacional como por industriales tributarios de las más dinámicas economías del primer mundo (Alemania, Estados Unidos, el Reino Unido, Francia y Suecia, entre otros). Había conseguido ya desarrollar una agricultura empresarial moderna, diversificada y en gran escala. Aunque seguía siendo una economía relativamente cerrada, había logrado establecer una pauta de exportaciones diferenciada que abarcaba desde los tradicionales productos primarios hasta las aeronaves, pasando por el sector de bienes de consumo duraderos y por la industria automotriz. Poseía uno de los mercados publicitarios más grandes del mundo y un sistema relativamente completo y diversificado de estudios de posgrado y de ciencia y tecnología. Su estructura ocupacional y de clases era diferenciada y se caracterizaba por una elevada movilidad geográfica y social, y por la presencia de una clase media ocupacionalmente diversificada y una clase operaria industrial, sobre todo en la región centro sur del país, de cierta importancia (Faria, 1986).

No obstante, al mismo tiempo el país todavía presentaba un grave cuadro de desigualdad, exclusión y atraso social, fruto de su pasado colonial y esclavista y del padrón excluyente de la industrialización protegida. En consecuencia, mostraba todavía un amplio sector rural empobrecido, formado por propietarios de pequeñas empresas familiares de bajísima productividad y por un contingente importante de trabajadores sin tierra. En las ciudades se aglomeraba un gran número de trabajadores manuales y no manuales sin calificación que constituían un amplio sector excluido y marginalizado. Los servicios de educación y de salud mostraban también un rezago considerable, tanto en el acceso a ellos como en sus niveles de calidad. La tasa de analfabetismo adulto era cercana al $20 \%$, y alcanzaba al $37 \%$ en el nordeste; la escolaridad media llegaba apenas a 4.9 años y el $11 \%$ de los niños de 7 a 14 años no iba a la escuela. Persistían padrones indeseables de discriminación social, basados especialmente en la raza, el género y el origen geográfico. La tasa de analfabetismo era de $9 \%$ entre los blancos y de $22 \%$ entre los negros y los mestizos. La población blanca en promedio había cursado 6.2 años de estudios, mientras que la de origen africano registraba 4.2 años. La mortalidad infantil, el desempleo y la falta de acceso a los servicios de salud también afectaban en mayor proporción a la población negra y mestiza que a la blanca. Cuando tenían empleo, los negros recibían la mitad del salario de los blancos.

Paradójicamente, lado a lado con una compleja estructura de exclusiones, rezagos, desigualdades, discriminaciones y vulnerabilidades, a fines del decenio de 1980 Brasil ya tenía un sistema estatal de protección social de alguna envergadura, sobre todo en comparación con los demás países de América Latina y los de Asia. Habiendo sido uno de los pioneros entre los países latinoamericanos que establecieron ese sistema - junto con Argentina, Uruguay, Chile y Cuba-, contaba ya con un sistema de protección amplio, complejo y caro. De fuerte inspiración bismarckiana y con una profunda influencia del padrón estatal-corporativo característico de los países en que el catolicismo ejerció un gran influjo político e ideológico, el sistema brasileño se caracterizaba y aún se caracteriza por beneficios desiguales y fragmentarios ligados a los distintos sectores ocupacionales y grupos de elite. Por su carácter marcadamente estatal, privilegiaba a los grupos vinculados al sector público: militares, personal del Estado (particularmente de las empresas estatales), funcionarios del cuerpo legislativo y judicial y de carreras típicas del Estado (como la diplomacia) y, en menor grado, trabajadores industriales de los sectores más estratégicos.

La incorporación progresiva de otros sectores se efectuó en forma desigual y el padrón de organización 
de los servicios sociales de responsabilidad pública siguió exhibiendo restricciones de acceso y de calidad, y, sobre todo en materia de educación, privilegió a los segmentos de clase media alta en su acceso a la enseñanza superior. La inversión y el gasto público requeridos por este sistema, considerando los tres niveles de gobierno (federal, estadual y municipal), representaban poco menos de $20 \%$ del PIB, estando la parte más significativa de este gasto relacionada con el sistema de jubilaciones y pensiones con cargo a los ingresos corrientes y con otros beneficios asociados al sistema corporativo.

La Constitución de 1988, fruto de la lucha contra el régimen autoritario, simplemente consagró y exageró los fundamentos de este sistema, sin considerar cabalmente su saneamiento actuarial, su impacto fiscal o su papel redistributivo, ni los desafíos que habría de enfrentar en el futuro, especialmente los derivados de la nueva dinámica demográfica. Innumerables diagnósticos sobre este sistema efectuados al despuntar el decenio de 1980 señalaban su carácter incompleto, corporativo, regresivo y fragmentario. ${ }^{1}$

La crisis de los años ochenta y primeros años del decenio de 1990 simplemente agravó este cuadro social, desorganizó el sistema de protección existente y acentuó las paradojas en un país profundamente desigual e injusto. Así, al agotarse el padrón de crecimiento basado en la industrialización sustitutiva dirigida por el Estado, que se caracterizó primero por la crisis de la deuda y después por la exacerbación hiperinflacionaria, el Brasil pasó por un período relativamente largo de fuertes oscilaciones en sus tasas de crecimiento que se tradujeron en más de diez años de estancamiento económico. La hiperinflación, atada a un índice, penalizaba fuertemente a los segmentos más pobres, incapaces de protegerse contra ella, y desorganizaba profundamente al sector público. En consecuencia, decayó aun más la calidad de los ya precarios servicios públicos, disminuyó en forma radical la inversión estatal y algunos sectores importantes de prestación de servicios públicos, como el habitacional, llegaron al colapso.

Así, al iniciarse el decenio de 1990 el país se encontraba sumido en una crisis sin precedentes. Entre fines del decenio de 1970 y los primeros años del de 1990 el ingreso familiar per cápita no llegaba a 250 reales la mayor parte del tiempo y, en promedio, en el período 1990-1994 se situaba prácticamente al mismo

\footnotetext{
${ }^{1}$ Véase en especial los trabajos de Draibe, Guimarães de Castro y Azeredo (1995) y Faria (1991a y b).
}

nivel que en 1977-1979 (gráfico 1). La proporción de pobres llegó a más de 50\% de la población durante la crisis de 1982-1983 y permaneció en torno al 43\% en los últimos años del decenio de 1980 y primeros del decenio siguiente (gráfico 2); en el primer semestre de 1994, inmediatamente después de adoptado el Plan Real, el número absoluto de pobres alcanzó su punto máximo: más de 67 millones de personas. Lo mismo ocurrió con la proporción y el número de indigentes. Al comenzar el decenio de 1990, la proporción de indigentes superó el $20 \%$ de la población $(20.4 \%$ en 1992) y su número absoluto se acercó a los 30 millones, siendo la proporción de 29.8\% en 1993-1994 (gráficos 3 y 4).

En los años iniciales de dicha década la esperanza de vida al nacer no llegaba a los 65 años; la mortalidad infantil (43 por mil para el país en su conjunto) todavía presentaba fuertes diferencias entre las zonas urbanas y las rurales y entre regiones, yendo desde 28 por mil en la zona urbana de la región sur hasta 84 por mil en el nordeste rural. Los índices de analfabetismo adulto y de escolaridad básica se situaban en niveles que no se compadecían con los grados de riqueza y desarrollo que había alcanzado el país: $17 \%$ de analfabetismo en la población adulta y poco más de cuatro años de escolaridad.

La distribución del ingreso en Brasil resume la gravedad del cuadro social. Después de cincuenta años de acentuado crecimiento, hacia fines del decenio de 1970 el coeficiente de Gini todavía se situaba en el

GRAFICO 1
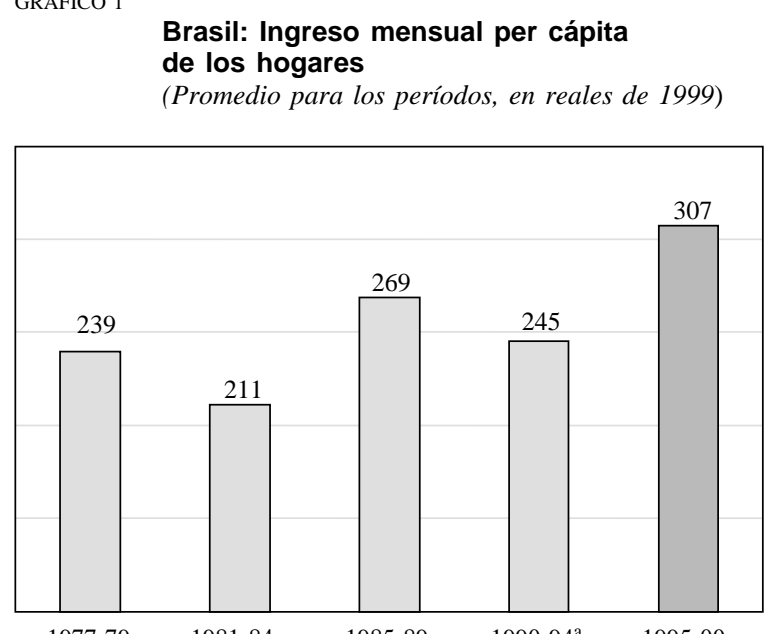

1977-79

1981-84

1985-89

1995-00

Fuente: Instituto Brasileño de Geografía y Estadística (IBGE), encuestas nacionales de hogares.

a No incluye el año 1991. 
GRAFICO 2

Brasil: Proporción de pobres en cada año, ${ }^{a}$ 1977-2000

(Porcentaje de la población total)

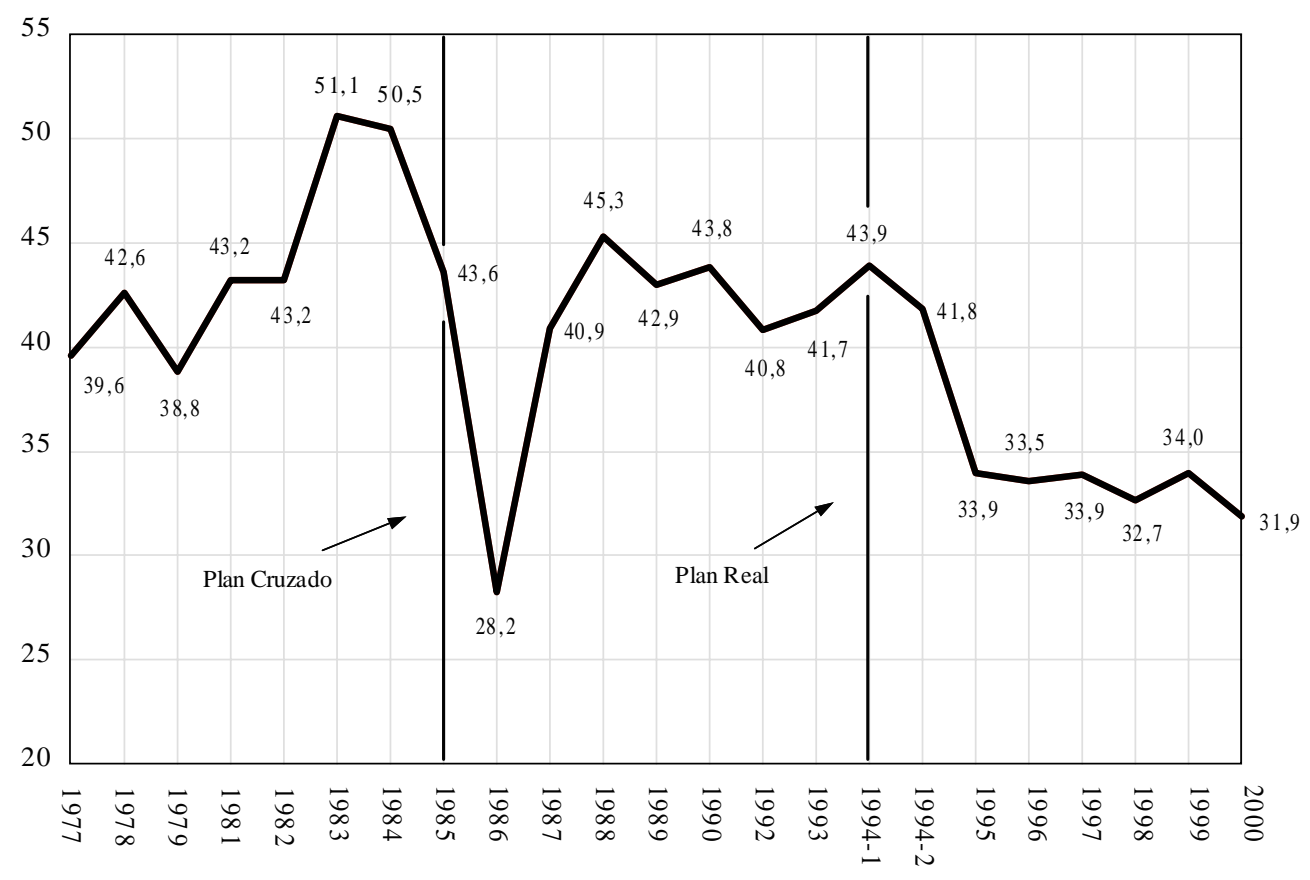

Fuente: Instituto de Investigación Económica Aplicada (IPEA), sobre la base de encuestas nacionales de hogares del IBGE.

a Los valores para los años 1994 a 2000 son estimados.

GRAFICO 3

Brasil: Proporción de indigentes, 1977-1999

(Promedios por períodos, en porcentajes de la población)

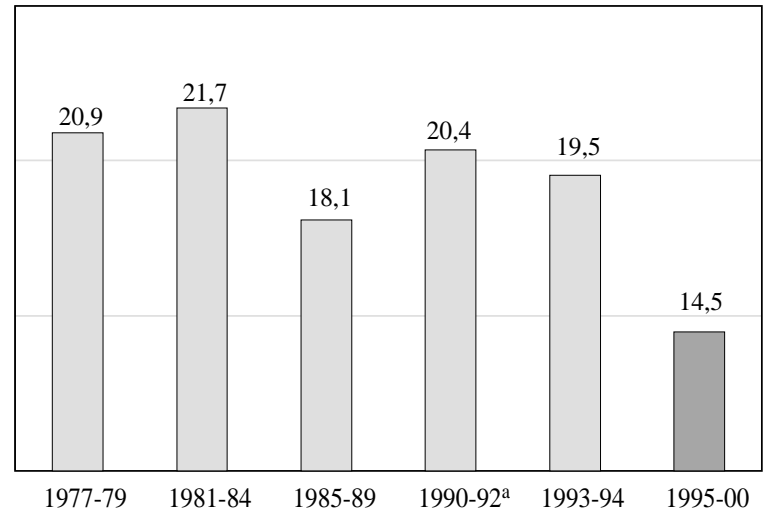

Fuente: IPEA, sobre la base de encuestas nacionales de hogares del IBGE.

a No incluye el año 1991.
GRAFICO 4

Brasil: Población total, población pobre y población indigente, entre 1977 y 2000

(Promedios por períodos, en millones)

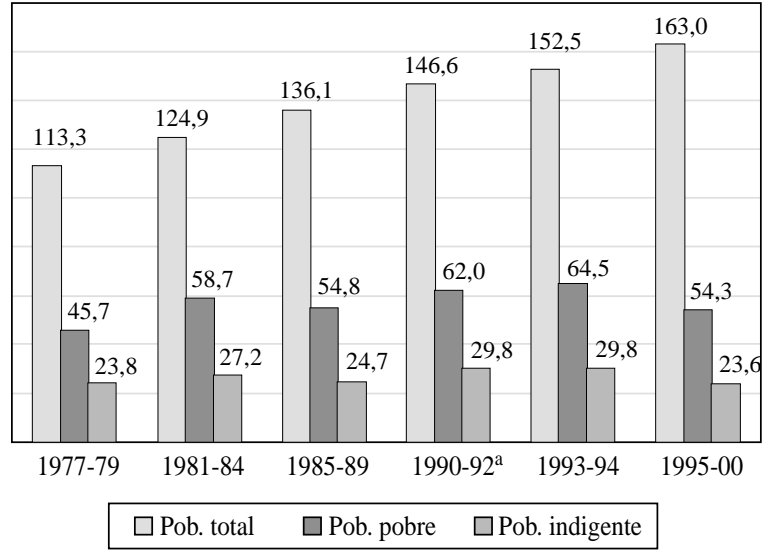

Fuente: IPEA, sobre la base de encuestas nacionales de hogares y censos del IBGE.

a No incluye el año 1991. 
tramo de 0.600 y permaneció estancado en este mismo nivel los veinte años siguientes, con un ligero agravamiento de la situación al comenzar la década de 1990 (gráfico 5).

Paradójicamente, sin embargo, el país gastaba cerca del 19\% del PIB en el área social, incluyendo jubilaciones y pensiones, salud, educación, trabajo, habitación y saneamiento básico, asistencia social, agricultura familiar, reforma agraria y desarrollo social rural. Esas inversiones y gastos, así como las transferencias directas de ingresos que de ellas derivaban, tenían escaso impacto distributivo. Las estimaciones existentes - hay que recalcar que son precarias- indican que en ese momento la pésima distribución del ingreso en el país permanecía casi inalterada antes y después de las transferencias gubernamentales.

Es en el contexto de este legado social, la grave crisis económico-social, las profundas transformaciones del padrón de crecimiento y de la organización del Estado, la urgente necesidad de resolver los problemas agudos de ajuste fiscal y de enfrentar las amenazas recurrentes derivadas de la inestable situación financiera internacional, que debe analizarse el desarrollo social de Brasil, los avances y las modificaciones necesarias en sus sistemas de protección social, las reformas institucionales requeridas y, principalmente, la coordinación de las políticas gubernamentales en el área social.

GRAFICO 5

Brasil: Distribución del ingreso: coeficiente de Gini, 1977-1999

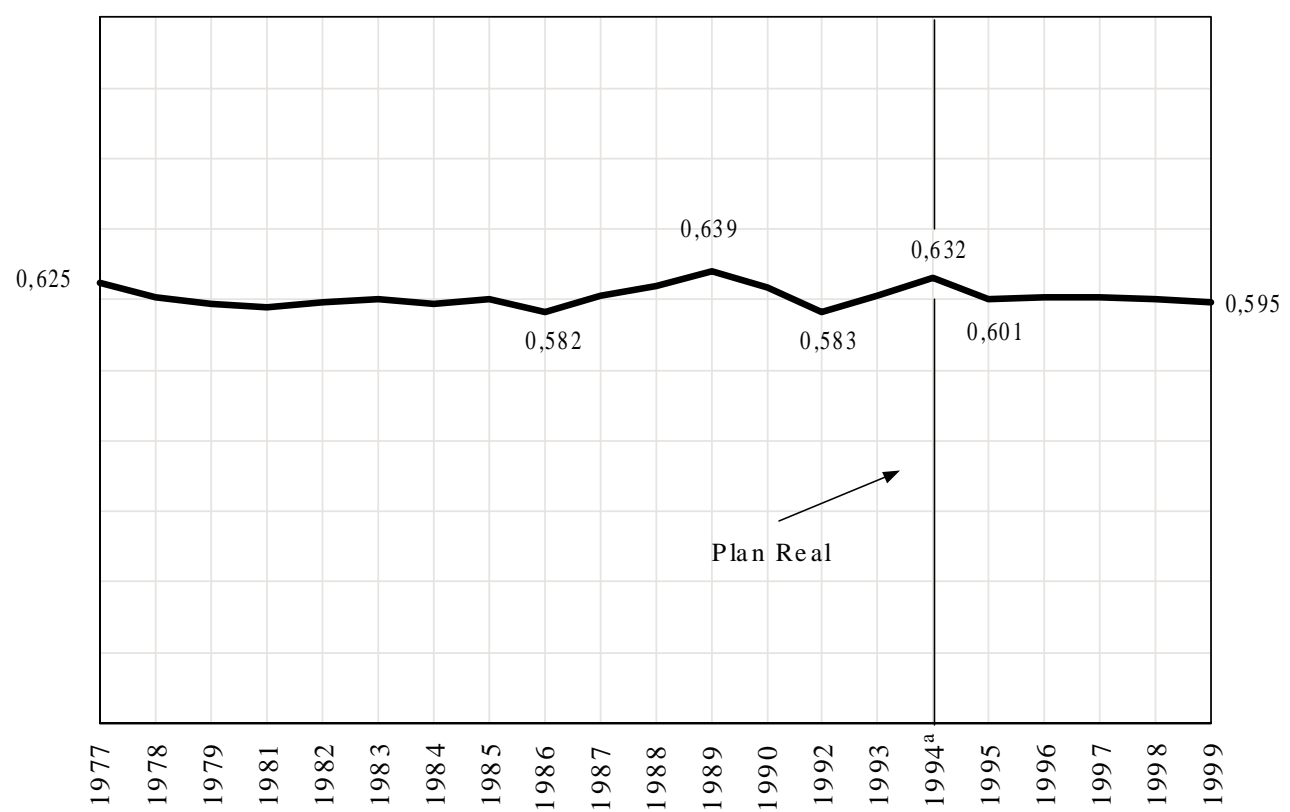

Fuente: IPEA, sobre la base de encuestas nacionales de hogares del IBGE.

a 1994: valor estimado.

\section{III}

\section{EI Plan Real y su estrategia de desarrollo social}

Después de innumerables tentativas infructuosas de ajuste estructural de la economía brasileña, de los desafíos planteados por las nuevas modalidades de divi- sión internacional del trabajo derivadas de la evolución del capitalismo mundial y de la desastrosa experiencia política del gobierno de Collor (1990-1992) que 
culminó con la destitución del Presidente de la República, se inició en Brasil la concepción, elaboración y aplicación progresiva del llamado Plan Real. Concebido bajo la dirección de Fernando Henrique Cardoso en el Ministerio de Hacienda durante el gobierno del Presidente Itamar Franco (1993-1994), ha sido aplicado desde entonces y se ha consolidado a lo largo de los dos mandatos del Presidente Cardoso (1995-2002).

Más conocido por sus aspectos económicos, especialmente en lo que se refiere a la lucha contra la hiperinflación y la estabilización de la moneda, el Plan Real fue enriquecido progresivamente. En primer lugar, se amplió para abarcar no sólo diferentes aspectos de las políticas monetaria, fiscal y cambiaria, sino también medidas encaminadas a la apertura de la economía y a lograr avances en el proceso de privatización y el fortalecimiento del sistema bancario. Luego se buscó englobar los aspectos relacionados con la reforma del Estado, las inversiones para adecuar la infraestructura física y social del país a los nuevos requisitos de acumulación de capital —en un plan plurianual de inversiones conocido como Avanza Brasil-y el fortalecimiento y la integración regionales en el Mercosur. Finalmente, y no menos importante, se incluyó la adopción de una amplia estrategia de desarrollo social.

Esta estrategia de desarrollo social, que fue concebida y aplicada en los años de gobierno de Cardoso, según se aprecia en los sucesivos documentos en que se plasmó, ${ }^{2}$ pone de relieve en primer lugar algunas condiciones que estima necesarias - aunque no suficientes - para promover el desarrollo social en forma sostenida. Enseguida, adopta algunos principios estratégicos como norte de las medidas que se han de aplicar y establece seis ejes en torno de los cuales se organizan las iniciativas institucionales y programáticas que dan cuerpo a la estrategia propuesta. Por último, con el correr del tiempo, desarrolla iniciativas constitucionales, institucionales, jurídicas y programáticas para alcanzar los objetivos perseguidos.

Desde el punto de vista programático, fueron cerca de cincuenta los grandes programas de gobierno que acabaron por dar vida en mayor o menor medida a la estrategia de desarrollo social. Ese aspecto menos conocido del Plan Real se resume a continuación.

Las condiciones fundamentales que serán garantizadas simultáneamente con el desarrollo de las políticas sociales son cuatro:

${ }^{2}$ Cardoso, 1994, 1998 y 2001; Brasil, Presidencia de la República, 1996 y 2001. i) Estabilidad macroeconómica. Como ha demostrado la experiencia brasileña reciente, el control de la inflación y la estabilidad de la moneda tienen un efecto redistributivo importante, aparte de contribuir a la estabilidad financiera y administrativa.

ii) Austeridad fiscal. El ajuste estructural de las cuentas públicas es el complemento indispensable de la estabilización de los precios, la modernización industrial, la desestatización y la reestructuración del sistema financiero para liberar y apoyar el potencial de crecimiento de la economía brasileña. Sin la consolidación de un nuevo régimen fiscal, la escasez de ahorro interno acabaría por inhibir el crecimiento de la producción y del consumo interno.

iii) Reforma del Estado. Se trata de una reforma funcional, con miras a reorientar la presencia del Estado hacia las actividades en que es esencial, y también de una reforma administrativa que apunta a capacitar el personal, reformar las carreras y dar nueva motivación a los funcionarios públicos con el fin de aumentar la eficacia del sector público, especialmente en los servicios sociales.

iv) Desarrollo económico sostenido. Es necesario volver a crecer a tasas no inferiores al $5 \%$ para enfrentar la tarea gigantesca de generación de nuevos puestos de trabajo en los próximos quince años y para elevar el PIB, lo que es esencial para mejorar la distribución del ingreso.

Los principios organizadores de la estrategia de desarrollo social son los que se enumeran a continuación:

i) Universalidad, solidaridad e igualdad de oportunidades. Estos principios deben orientar las políticas sociales sin perder de vista la relación costo-eficacia de cada uno de los programas.

ii) Participación. En el diseño, aplicación y evaluación de las políticas sociales es fundamental la ampliación de los espacios públicos, aumentando y diversificando las formas de participación social y control público.

iii) Descentralización. En un país tan grande y heterogéneo como es Brasil, con una fuerte estructura federalista, la descentralización es absolutamente necesaria para la ejecución de políticas públicas en el área social. Sin perder de vista la importancia estratégica del poder central por su papel redistributivo - regional y social - la participación directa de Estados y municipios es esencial en sectores como la educación y la salud.

iv) Asociación. Sabiendo que el gobierno no puede encargarse por sí solo de la gran cantidad de tareas necesarias para llevar a cabo una política social 
coherente, es fundamental contraer compromisos con la sociedad civil, representada por empresas, sindicatos, iglesias, universidades, organizaciones no gubernamentales. Por medio de esos acuerdos se podrá desarrollar nuevas formas públicas, no necesariamente estatales, para enfrentar los problemas (por ejemplo, en áreas de la salud).

Los ejes estructuradores de la estrategia social brasileña son los siguientes:

i) Profunda reforma de los servicios sociales básicos de responsabilidad pública. A través de la universalización de la cobertura en materia de educación, salud, seguridad social básica e infraestructura urbana; el mejoramiento de la calidad de los servicios; una mayor eficiencia, y el mayor impacto redistributivo del gasto social.

ii) Mejoramiento de la cantidad y la calidad de las oportunidades de trabajo y de obtención de ingresos. Esto incluye tanto un mayor apoyo a los sectores que hacen uso intensivo de mano de obra como la formación y recapacitación profesional y la enmienda de la legislación que regula las relaciones del trabajo con la ampliación de los denominados contratos laborales colectivos.

iii) Aplicación de políticas específicas para el campo. A pesar de la creciente urbanización de Brasil, cerca de $25 \%$ de la población económicamente activa está empleada en la agricultura y parte significativa de la población que emigró a las ciudades no ha conseguido incorporarse en forma adecuada en las estructuras productivas urbanas. Por lo tanto, apoyar la agricultura familiar y estimular nuevas formas de sobrevivencia en empresas agrourbanas son tareas esenciales.

iv) Aumento de las oportunidades de acceso a activos productivos como la tierra, el crédito y los conocimientos. v) Desarrollo de iniciativas y programas destinados específicamente a aliviar, a corto plazo, la situación de pobreza más aguda. En Brasil los programas focalizados implican flexibilidad, porque no serían adecuadas las mismas políticas para la periferia de una gran ciudad como São Paulo y para el interior del nordeste. El Programa Comunidad Solidaria fue concebido para articular los programas de lucha contra la miseria y el hambre en las regiones más pobres del país y para ensayar nuevas iniciativas sociales junto con la sociedad civil.

vi) Establecimiento y mejora de los programas de transferencia directa del ingreso. Estos programas constituyen una suerte de sistema de protección social para situaciones de necesidad y de riesgo. Los principales son: renta mensual vitalicia para los ancianos y los discapacitados, que garantizan a más de un millón de ancianos y personas pobres discapacitadas un salario mínimo mensual con un costo anual de $3500 \mathrm{mi}-$ llones de reales; previsión rural con beneficios concedidos a más de seis millones de trabajadores del campo con un costo de 12000 millones de reales anuales; seguro de desempleo y suplemento salarial que suponen recursos anuales de 5000 millones de reales, y el programa Bolsa-Escola (beca-escuela) con recursos del orden de 2500 millones de reales traspasados por el gobierno federal a los municipios. En total, el costo de los programas federales de transferencia directa de ingresos ascendería en 2001 a cerca de 20000 millones de reales, lo que representa más de $2.5 \%$ del PIB.

Esta estrategia tan amplia y ambiciosa fue adquiriendo contornos más definidos con el tiempo, pero todavía subsisten lagunas importantes en su aplicación. En algunos de sus objetivos programáticos no tuvo gran éxito y, sobre todo, continúa enfrentando serios estrangulamientos de orden fiscal y diversos desafíos de naturaleza constitucional, jurídica e institucional.

\section{IV}

\section{Los aspectos institucionales de la estrategia de desarrollo social}

Eran y siguen siendo numerosos los obstáculos y puntos de estrangulamiento que habrá que superar si se intenta aplicar una estrategia de desarrollo social como la que exige la situación brasileña y que acabamos de resumir.
En el plano fiscal, se imponen limitaciones por lo menos desde dos lados. Por una parte, se plantea la necesidad de llevar adelante una política de austeridad fiscal como condición necesaria - aunque no suficiente- para alcanzar el desarrollo social sostenido, lo que 
supone severas restricciones al gasto público federal, estadual y municipal reforzadas por la adopción de la Ley de Responsabilidad Fiscal, dura pero indispensable. Por otra parte, impone limitaciones el gran esfuerzo de gasto ya realizado y su casi ineludible crecimiento vegetativo como consecuencia de la dinámica demográfica, especialmente en las áreas de previsión y asistencia social y en la de salud. Desde el punto de vista macroeconómico, sería muy difícil aumentar el monto de la inversión y gasto sociales, que se sitúa ya en torno al $22 \%$ del PIB, pues se sabe que mientras más alto es el nivel de este esfuerzo más difícil resulta elevarlo. Las restricciones señaladas acotan significativamente el radio de maniobra para mejorar las políticas de protección social.

Sin embargo, es en el plano institucional -incluyendo en él los aspectos jurídicos, políticos y de organización- donde se encontraban y todavía se encuentran los principales obstáculos por vencer.

Para comenzar, como señalamos antes, el sistema brasileño de protección social heredado del pasado forma parte del problema, no de la solución. Caracterizado por su índole corporativa y fragmentaria, por su elevado costo e ineficiencia operacional, así como por la constelación de intereses que se formó a su alrededor (políticos, burócratas, proveedores y clientes), su estructura regresiva de beneficios se cristaliza en un conjunto de derechos adquiridos y de privilegios conquistados, especialmente por segmentos de clase media bien colocados en las estructuras judicial, política, burocrática y militar del país.

En segundo lugar, bajo el impulso del proceso de redemocratización gatillado en gran medida por la mala calidad, deficiente desempeño, acceso restricto y deterioro de los servicios sociales de responsabilidad pública asociados con la crisis que se fue agudizando a fines del decenio de 1970, la nueva Constitución de Brasil enriqueció las bases jurídicas del sistema de protección social, al introducir en el texto constitucional, en forma minuciosa, requisitos específicos de protección, de difícil cumplimiento en las nuevas condiciones de competitividad, dinámica demográfica y austeridad fiscal.

En tercer lugar, la propia consolidación de la democracia y el saludable dinamismo y combatividad consiguientes de los distintos sectores de la sociedad brasileña han ido transformando en presiones organizadas y legítimas las múltiples demandas que derivan de la injusta situación social, particularmente en lo que se refiere a la lucha contra el hambre, la exclusión, la discriminación y la pobreza, y exigen políticas bien enfocadas y medidas de acción afirmativa.
Por último, y como síntesis de todo lo anterior, cuando no hay campo para incrementar los gastos o efectuar una expansión mediante mecanismos de equiparación por arriba, lo que permitiría que la expansión se diera como un juego de suma positiva, a la política social sólo le queda el camino de reestructurar el financiamiento, los gastos y los beneficios, con el propósito de aumentar su eficacia, cobertura e impacto redistributivo. Es decir, sólo le resta introducir profundas modificaciones de orden institucional que suponen grandes conflictos de intereses.

Sería largo y tedioso analizar los pormenores de esa vasta reforma institucional que se está llevando a cabo mediante el diálogo, el debate y la lucha democrática. Aquí sólo queremos señalar sus principales dimensiones y campos de acción.

En primer lugar, fue necesario - y lo sigue siendo- modificar el sistema de financiamiento de las políticas sociales y los mecanismos de distribución de recursos y asignaciones entre las distintas esferas de gobierno. Al respecto hubo iniciativas importantes relativas a la previsión social de los trabajadores del sector privado; a la manera de financiar y redistribuir los recursos federales para los estados y municipios en los sectores de educación y salud, como la creación del Fondo para la Mantención y Desarrollo de la Enseñanza Básica y Valorización del Magisterio y la del Piso de Asistencia Básica (PAB); a la obtención de nuevas fuentes de recursos para financiar los gastos de salud, como el establecimiento de la Contribución provisional sobre los movimientos financieros (CPMF), y a la creación de un fondo para los programas especiales de lucha contra la pobreza (Fondo de Combate de la Pobreza).

En segundo lugar, fue necesario -y de nuevo sigue siéndolo - efectuar una profunda reforma de las instituciones previsionales, tanto las que atienden a los trabajadores del sector privado como, y sobre todo, las que sirven a los distintos segmentos del sector público. Aquí, por la amplitud y alcance de la reforma y por el conflicto de intereses que implica, algo se avanzó en lo que toca a la previsión para los trabajadores del sector privado, con la modificación de los criterios de edad y de tiempo de contribución y de servicio para obtener prestaciones, pero poco se ha conseguido hasta ahora en lo que se refiere a la previsión para los empleados del sector público.

En tercer lugar, para muchas de estas reformas hubo que modificar el texto constitucional, lo que exigía el apoyo de $3 / 5$ de los votos en ambas cámaras y la anuencia de las instancias superiores del Poder 
Judicial. En un sistema político que cuenta con más de treinta partidos, que se caracterizan —incluso los seis o siete más importantes- por el personalismo y la indisciplina partidaria y en el cual el apoyo parlamentario para el gobierno se organiza sobre bases efímeras y frágiles, efectuar reformas de esta índole exige siempre un gran empeño y supone un constante desgaste político. Por otra parte, algunas de estas medidas afectan los intereses de las ramas legislativa y judicial, lo que dificulta su acogida en estos circuitos del Estado. El gobierno de Fernando Henrique Cardoso, aunque tuvo bastante buen éxito en la aplicación de estas reformas — también necesarias en otras esferas implícitas en la ejecución del Plan Real- no pudo eludir ese desgaste y sufrió una que otra derrota importante, como, por ejemplo, respecto a la contribución de los inactivos del sector público.

Por último, importa destacar que la ejecución de una estrategia de desarrollo social como la que se fue perfilando en la segunda mitad del decenio de 1990 en Brasil, exige esfuerzos redoblados de articulación y coordinación intragubernamentales e intergubernamentales. Queremos seguir analizando este aspecto, que es el tema principal del presente artículo.

\section{$\mathrm{V}$}

\section{Articulación y coordinación de las políticas de protección social. ¿Basta una autoridad social?}

Está de más insistir en la importancia que tienen en cualquier área los mecanismos de articulación y coordinación de políticas. Esa importancia, sin embargo, aumenta en función de algunos factores como los siguientes: tamaño y heterogeneidad del país; complejidad y diferenciación institucional del aparato estatal o público responsable de las políticas; volumen y complejidad de los recursos financieros en juego; forma de organización estatal (Estados unitarios, federados o confederaciones); sistemas y regímenes de gobierno (democracias o dictaduras, monarquías constitucionales, presidencialismo de coalición, regímenes parlamentarios, presidencialismo bipartidario, etc.) y las modalidades prevalecientes de la oferta de servicios públicos (estatal centralizada, estatal descentralizada, pública descentralizada, liberal filantrópica, liberal de mercado, etc.). Estos factores, a su vez, inciden en la definición de los principales problemas de articulación y coordinación de políticas y, por ende, en las posibles soluciones.

Basándonos en nuestra propia experiencia de la gestión y evaluación de políticas sociales en Brasil, podemos ofrecer aquí algunas luces sobre su evolución reciente.

Brasil, país de dimensiones continentales, se caracteriza por un federalismo singular y fuerte: los entes federados, aparte la Unión, son 27 estados, un distrito federal y casi 6000 municipios; por una democracia incipiente, pero pujante, que cuenta con un Congreso Nacional (Senado y Cámara Federal) activo en el que están representados más de veinte partidos, con un sistema judicial complejo y diferenciado, y con una prensa libre y agresiva; y por un sistema de gobierno basado en elecciones libres y competitivas, donde los ejecutivos de la Unión, de los estados y de los municipios mayores son escogidos en elecciones periódicas, en dos tandas. El sistema de gobierno puede ser definido, en el plano federal, como un "régimen presidencial de coalición" que supone la formación de complejas e inestables alianzas políticas tanto para ser elegido como, principalmente, para gobernar.

Las responsabilidades de ejecución de los diferentes elementos de la política social brasileña -que supone recursos anuales superiores a los 300000 millones de reales- se reparten entre la Unión, los estados y los municipios. En el plano federal, el presupuesto social, que representa cerca del $80 \%$ del presupuesto total de la Unión (170 000 millones de reales de un total de 210000 millones en el año 2000), se distribuye entre unos diez ministerios. Cinco de ellos -Previsión y Asistencia Social, Salud, Educación, Agricultura Familiar y Reforma Agraria, y Trabajo y Empleo- son grandes estructuras burocráticas, poseen tradición e influencia, mueven ingentes recursos y son responsables del financiamiento y control normativo de políticas y programas que, en conjunto, atienden a más de 150 millones de personas.

Llevar a cabo los más de cincuenta programas en que se traduce el conjunto de medidas de protección social supone complejas relaciones interguberna- 
mentales en el plano federal, y no menos complejas relaciones intergubernamentales con los demás entes de la federación. Además, buena parte de los programas cuenta todavía con consejos normativos o reguladores, compuestos, en proporciones variables según el consejo, por representantes del Gobierno Federal, de los estados, de los municipios, de segmentos sociales específicos - como los empresarios y los trabajadores- y de la sociedad civil en general. Con frecuencia, esos consejos se desdoblan en consejos federales, estaduales y municipales.

Por todas esas características, que sin duda no son privativas de Brasil, el diseño y la preparación del presupuesto, la reglamentación, la ejecución y la evaluación de las políticas sociales suponen problemas de articulación y coordinación nada triviales, que se multiplican por las exigencias del proceso en curso de reestructuración del sistema de protección social, asociado con el Plan Real.

Destacaremos a continuación cuatro aspectos del tema en la experiencia brasileña reciente, describiendo en forma escueta las iniciativas tomadas y evaluando - en un primer intento- sus éxitos y fracasos.

El primer aspecto, más general y determinante, es el de los problemas de articulación y coordinación macropolíticas, especialmente en lo que toca a financiamiento y presupuesto, por un lado, y a articulación política para llevar adelante las reformas deseadas, por el otro.

En el caso brasileño, las estructuras encargadas de desempeñar estas funciones se ubican en la Presidencia de la República, y reciben un mandato explícito, junto con el apoyo y la participación directa del Presidente, o se reparten entre el Departamento Civil, la Secretaría General de la Presidencia de la República, la Abogacía General de la Unión y la Asesoría Especial del Gabinete del Presidente. Cabe al Ministro Jefe de la Secretaría General de la Presidencia de la República articular y coordinar las relaciones entre el Ejecutivo y el Congreso, con los gobernadores de los estados y con los partidos políticos. La Abogacía General de la Unión y la Asesoría Especial, además de sus funciones específicas, ayudan al Presidente y a los ministros en la ejecución de esas tareas de coordinación y articulación.

En este aspecto, la iniciativa más importante encaminada a mejorar el desempeño de la administración federal fue la creación de las cámaras sectoriales, en que se reúnen grupos de ministros por áreas temáticas o macroproblemas, bajo el mando operacional del Ministro Jefe del Departamento Civil. Desde un co- mienzo se crearon las siguientes cámaras sectoriales: Cámara de Políticas Económicas, Cámara de Infraestructura, Cámara de Políticas Sociales, Cámara de Reforma del Estado, y Cámara de Seguridad y Justicia. Ellas se reúnen con regularidad — semanal o quincenalmente - y están formadas por el Ministro Jefe del Departamento Civil — que las coordina—, por el Secretario General, por el Ministro de Hacienda, el Ministro de Presupuesto, Planeamiento y Gestión, por los ministros sectoriales y por los presidentes de organismos autárquicos y bancos estatales, cuando corresponda. Algunas de esas cámaras cuentan además con un secretario ejecutivo, responsable de dar curso a las decisiones que ellas adopten. El Presidente de la República participa activamente en estas reuniones, con la frecuencia que estime necesaria el Ministro Jefe del Departamento Civil y el secretario ejecutivo de la cámara respectiva. Organizadas al principio con una composición fija, la experiencia mostró que era más conveniente que ella variara en función de los problemas de articulación y coordinación que correspondiera tratar.

Los resultados de estas cámaras fueron muy desiguales. Entre las mejor logradas figuran la Cámara de Política Económica — que se reúne semanalmente, casi siempre con la presencia del Presidente de la República-, la Cámara de Infraestructura y la Cámara de Política Social.

La Cámara de Política Social ha servido de mecanismo de articulación y coordinación de la estrategia de desarrollo social que se está aplicando en Brasil. Su éxito relativo, sobre todo en los años iniciales de establecimiento y aplicación de esa estrategia, se debe fundamentalmente a cuatro factores, todos ellos de carácter político: empeño de las autoridades centrales del gobierno, especialmente de la Presidencia de la República; convergencia de perspectivas, no sin conflictos y arduas negociaciones, entre los ministros de las principales áreas sociales (previsión, salud, educación, trabajo, agricultura familiar y reforma agraria); una mayoría formada por técnicos de reconocida capacidad y hombres de la estricta confianza del Presidente de la República; y la sensibilidad y disciplina que han mostrado las autoridades económicas — no sin conflictos y desacuerdos- frente a las decisiones tomadas en la cámara y refrendadas por el Presidente de la República, aunque no siempre ha prevalecido el punto de vista de las áreas sociales.

En este aspecto, la experiencia brasileña reciente no consagra como una alternativa necesaria, ni siquiera deseable, la creación de una "autoridad social", 
entendida como una superestructura burocrática, bajo el control de un ministro, que reúne poderes operacionales en algunas o en todas las áreas sectoriales de la política social. Una iniciativa de ese tipo no sería políticamente viable y resultaría operacionalmente ineficaz. Por otro lado, a diferencia de lo que ocurre en el área económica, donde los mecanismos de operación son relativamente pocos y altamente eficientes - el presupuesto, la tasa de interés, el tipo de cambio y el control de los ingresos, entre otros-, en el área social estos instrumentos son mucho más numerosos y de eficiencia más restringida. Por otro lado, buena parte del cuerpo técnico operacional se encuentra en los ministerios sectoriales; por deteriorado que se encuentre actualmente, al centralizarlo en una superestructura sólo se aumentaría su ineficiencia. La experiencia brasileña apunta en otra dirección: reformar y fortalecer las estructuras sectoriales desde el punto de vista funcional y técnico, dotarlas de fuerza, prestigio y poder políticos y desarrollar mecanismos y no estructuras burocráticas de articulación y coordinación.

Un segundo aspecto importante del problema de la articulación y la coordinación se refiere a las actividades de protección social que suponen conflicto y necesitan, para la ejecución de un programa o proyecto, de la colaboración entre diferentes sectores del área social del Gobierno Federal. Buena parte de estos programas y proyectos, sobre todo los más innovadores que apuntan a reformar el perfil de la política social brasileña, suponen esa colaboración. Así, por ejemplo, el programa Bolsa-Escola requiere la colaboración operacional estrecha entre los Ministerios de Educación, de Previsión y Asistencia Social, y de Justicia, así como de la Caja Económica Federal.

El mecanismo que desarrolló el Gobierno Federal para lidiar con esos problemas de coordinación nació en el seno de la Cámara de Política Social. Fue creado por un comité ejecutivo de la cámara y coordinado por su secretario; se le dio un formato flexible, orientado a resolver los problemas de los secretarios ejecutivos de los respectivos ministerios, cuya función básica es llevar a la práctica las políticas, programas y proyectos. Los problemas de integración, articulación y coordinación operacional que no encuentran solución en esta etapa son llevados a la instancia ministerial de la Cámara.

El éxito de esta iniciativa, aunque mayor que el de la coordinación macropolítica, también varió de un programa a otro, lo que también se debió más bien a factores de índole político-administrativa que a facto- res de centralización burocrática. Entre ellos cabe mencionar la capacidad técnica y de gestión de los secretarios ejecutivos sectoriales, una continuidad administrativa relativamente prolongada, la convergencia de perspectivas respecto a las orientaciones de la estrategia de desarrollo social, el apoyo político recibido por los secretarios ejecutivos de parte de sus respectivos ministerios, y la legitimación que consiguieron junto con sus respectivos aparatos administrativos.

Un tercer aspecto de la coordinación de las políticas sociales en el plano federal se refiere a problemas relacionados con la orientación regional y social de los programas y su convergencia. Los diagnósticos críticos de la política social brasileña siempre plantearon, entre otros, dos grandes problemas: la falta de focalización de algunos programas para combatir la pobreza y la desigualdad regional, por un lado, y la falta de sinergia y convergencia de los programas, por otro. Los sectores más desposeídos de la población brasileña no tenían acceso a las iniciativas de protección social, faltaban programas focalizados, y muchos programas convergían en unas pocas áreas y sectores, dejando excluidos a muchos otros, sobre todo los más pobres y desfavorecidos. La reforma del sistema brasileño de protección exigía un esfuerzo de focalización de algunos programas y su sinergia y convergencia en áreas consideradas prioritarias por sus carencias. Cabe mencionar que buena parte de estos programas son de naturaleza sectorial y que la capacidad técnica y operacional para ejecutarlos se encuentra en las estructuras administrativas sectoriales. Además, para llevarlos a cabo, aparte la articulación interministerial, son decisivas la articulación y la coordinación intergubernamentales.

Por experiencia propia — sobre todo con iniciativas frustradas de este tipo tomadas en al ámbito de la Secretaría de Acción Comunitaria en los primeros tiempos de la democratización - y sobre la base de algunas experiencias de los fondos sociales que proliferaron en el decenio de 1980, los gestores brasileños habían descartado concentrar estos programas focalizados y estos mecanismos de convergencia en un organismo único. El clientelismo en el seno de ese tipo de organismo, la desvalorización aun mayor de los órganos sectoriales, el abandono de la capacidad técnica, política y administrativa acumulada sectorialmente y los conflictos burocráticos implícitos en una solución de esta índole recomendaban buscar nuevas alternativas.

Con el tiempo, el Gobierno Federal brasileño consiguió desarrollar un conjunto de procedimientos, 
mecanismos y estructuras para hacer frente a esta difícil cuestión. El punto de partida fue la creación de un programa, en el ámbito del Departamento Civil de la Presidencia de la República, conocido como el Programa de Acción Solidaria, que luego de pasar por varias etapas se ha desdoblado en tres o cuatro mecanismos y estructuras.

Por un lado, el Gobierno Federal creó —dándole apoyo logístico y administrativo- un Consejo, integrado actualmente por cuatro ministros (del Departamento Civil, de Hacienda, de Planeamiento y de Justicia), por veinte ciudadanos de distintos segmentos de la sociedad civil con reconocida participación en iniciativas para combatir la exclusión y la pobreza, y por Ruth Cardoso, antropóloga y profesora universitaria, con larga trayectoria de militancia en movimientos sociales y primera dama de la nación. A partir de este Consejo se establecen asociaciones entre los programas gubernamentales (federales, estaduales y municipales), los programas sectoriales y distintos sectores de la sociedad civil (empresas, universidades, sindicatos, iglesias, etc.), con el objeto de desarrollar actividades de política social de carácter innovador junto con segmentos y regiones seleccionados por sus necesidades y carencias. Algunas de las iniciativas bien logradas en este ámbito son: los programas de alfabetización de jóvenes, financiados por empresas del sector privado con el apoyo del Ministerio de Educación; los programas de capacitación profesional de jóvenes, desarrollados por organizaciones no gubernamentales, prefecturas y sindicatos, con al apoyo de empresas privadas y del Ministerio del Trabajo; los programas de incentivo para la acción voluntaria, con el apoyo del Ministerio de Justicia, y un programa de movilización de la comunidad universitaria para la ejecución de proyectos de desarrollo comunitario, con el apoyo del Ministerio de Salud y del de Educación, las fuerzas armadas y las empresas privadas. Esas iniciativas, que en general comenzaron experimentalmente y en pequeña escala, al tener éxito se generalizaron e incorporaron a distintos segmentos, tanto del sector público como del privado y del llamado tercer sector.

Después de algunas experiencias frustradas, el Gobierno Federal lleva adelante hoy dos iniciativas, ambas coordinadas por la Presidencia de la República, bajo la responsabilidad operacional de un ejecutivo nombrado por el Presidente, que tienen como objetivo llevar adelante de manera coordinada y sinérgica un subconjunto de programas para las zonas más pobres del país, escogidas según indicadores sociales como los que integran el índice de desarrollo humano elaborado por el PNUD, y disponibles para todos los municipios del país.

La primera, llamada Proyecto Alborada, consiste en un conjunto de doce programas elaborados en el ámbito de los Ministerios de Educación, de Salud, de Previsión y Asistencia Social, y de Deporte y Turismo, entre otros. La apoya un Fondo de Combate contra la Pobreza, creado por el Congreso Nacional, que tiene por objetivo dotar a los municipios brasileños cuyo índice de desarrollo humano sea bajo (menos de 0.500) de la infraestructura básica necesaria para las actividades de desarrollo social y humano. Los programas siguen siendo ejecutados sectorialmente. El objetivo de la iniciativa es lograr que estos programas sectoriales lleguen prioritariamente a esos municipios y que allí sean ejecutados coordinadamente por las autoridades y por la sociedad civil local. Sus problemas de articulación intersectorial se tratan y resuelven en el ámbito de la secretaría ejecutiva de la Cámara de Política Social.

La segunda iniciativa, que es parte de un programa denominado Comunidad Activa, tiene cobertura y alcance más reducidos y está orientada a apoyar actividades comunitarias de desarrollo local integrado. En cada estado se eligen aquellos municipios más pobres cuyas comunidades hubieran revelado alguna capacidad de movilización, organización y acción, con el fín de encontrar nuevas formas de dinamizar y desarrollar sus respectivas regiones. Sobre la base de la organización y la capacitación microempresarial (empuje) de estas comunidades, se identifican vacíos y demandas, y el Gobierno Federal procura movilizar sus programas para apoyar tales esfuerzos de desarrollo local.

Como puede verse, más que estructuras burocráticas centralizadas, estas iniciativas apuntan a crear mecanismos de articulación y coordinación intergubernamentales e intragubernamentales, con el apoyo político de las autoridades del gobierno central.

Un cuarto aspecto de la coordinación de las políticas sociales se refiere a la continuidad y la eficacia administrativa de los programas sociales. Desde el punto de vista presupuestario, se trata de crear mecanismos que protejan los principales programas sociales de las variaciones cíclicas y los recortes de gasto que puedan imponer periódicamente las exigencias de equilibrio fiscal. En este campo se han tomado dos iniciativas, ambas en el ámbito del Ministerio de Planeamiento, Presupuesto y Gestión. 
La primera, el programa llamado Avanza Brasil, abarca un subconjunto seleccionado de programas - cincuenta programas en las diversas áreas consideradas prioritarias por el gobierno y que comprenden infraestructura, desarrollo social y generación de conocimientos- que tienen prelación presupuestaria y para los cuales se desarrollaron mecanismos especiales de gestión, seguimiento y evaluación. También forma parte de esta iniciativa otro grupo de doce programas, cuyas partidas presupuestarias se mantuvieron incluso en diversas circunstancias que impusieron un recorte de los gastos.

La segunda, llamada Red de Protección Social, se desarrolló en el contexto de las negociaciones que llevó adelante el Brasil en 1998 con el Fondo Monetario Internacional (FMI), el Banco Mundial y el Banco Interamericano de Desarrollo (BID), con el objeto de obtener el apoyo de estos organismos para proteger a la economía brasileña de los embates especulativos y de las crisis financieras que periódicamente amenazan a las economías emergentes. Como parte de los compromisos asumidos por el país, junto con las metas de control de la inflación y reducción del déficit público, se asumieron compromisos y metas físicas y financieras para veintidós programas considerados esenciales para proteger a diversos segmentos más pobres de la población en esas coyunturas de crisis (por ejemplo, mantenimiento de los recursos para el pago del seguro de desempleo y de la renta mensual de los ancianos y los discapacitados pobres, y los recursos para el financiamiento de la enseñanza básica).

Aquí, nuevamente, prevalece la creación de mecanismos operacionales y con respaldo político, más que de estructuras burocráticas centralizadas.

Por último, valga una palabra sobre otro aspecto de la articulación y la coordinación de las políticas sociales: las relaciones entre los diversos niveles de gobierno. En el Brasil, aunque el papel del Gobierno Federal siempre ha sido - y deberá seguir siendoestratégico en el financiamiento y la creación de directrices normativas para los programas de protección social, la ejecución operacional de los programas de protección social se da en forma crecientemente descentralizada y queda a cargo de los estados y municipios. Esa necesidad de descentralización — pues el ciudadano no vive en la Unión, sino en los municipios- en un país tan grande como el Brasil y con su peculiar sistema federal, plantea enormes problemas de coordinación y articulación. Aunque están en marcha numerosas iniciativas para hacer frente a estos problemas, por su dispersión y por la permanencia de las dificultades en este nivel, no creemos que pueda aprovecharse la experiencia brasileña para sugerir algún proyecto de mayor envergadura, que hubiera tenido éxito aparte del que suponen las experiencias que acabamos de relatar.

Nuestra conclusión personal y pragmática basada en los problemas de un país como el Brasil no apunta a estimar necesario - ni siquiera conveniente- la creación de una "autoridad social" centralizada, si por ello se entiende el establecimiento de nuevas estructuras burocráticas que concentren y centralicen las iniciativas de política social. Aparte del empuje político por parte de las autoridades centrales, lo que se requiere es la creación de mecanismos de coordinación y articulación, dotados de legitimidad, apoyo político y capacidad técnica.

Nuestra experiencia también sugiere que la recuperación y valorización funcional, técnica y administrativa de los órganos sectoriales es un aspecto fundamental para mejorar la actuación de los gobiernos en el área social. En este sentido, parte de las actividades de reforma del Estado y de mejoramiento de su gestión deben orientarse a la valorización de los empleados públicos que se dedican a las actividades finales (profesores, médicos, asistentes sociales, etc.) así como a la mejor preparación profesional de los que se dedican a las actividades instrumentales en estos sectores (gerentes, gestores, personal de recursos humanos, de informática, etc.), estimulando y premiando una competencia saludable, el buen desempeño y el progreso en las carreras. A nuestro entender, mientras sigan pesando las dificultades derivadas de la existencia de burocracias antiguas y viciadas que se deterioran con la desvalorización de la función pública, estarán condenadas al fracaso las estrategias basadas en la idea de crear estructuras nuevas y dejar que las antiguas se derrumben por abandono o cesación.

Por último, deseamos señalar la importancia de formar un equipo social políticamente cohesionado, que se identifique con la estrategia de desarrollo social propuesta por el jefe del poder ejecutivo y que sea técnicamente competente, para que tengan éxito los mecanismos de coordinación y articulación. 


\section{VI}

\section{Conclusión: somero balance de los resultados obtenidos}

No es éste el lugar para evaluar en detalle los resultados de la política social brasileña en los últimos diez años. Cabe, sin embargo, llamar la atención sobre tres aspectos a título de conclusión.

En primer lugar, persisten grandes desafíos que deberán ser enfrentados, sea en el campo del mejoramiento de los diversos indicadores sociales, sea en materia de cobertura, eficacia y calidad de los servicios sociales de responsabilidad pública, especialmente salud, educación y seguridad pública, sea en los mecanismos de articulación y coordinación de políticas o incluso en la reforma del sistema brasileño de protección social, especialmente en lo que se refiere a su papel redistributivo.

En segundo lugar, es preciso reconocer que todavía queda mucho por hacer, pero que los resultados objetivos del Plan Real en el área social son indiscuti- bles. A pesar de las dificultades presupuestarias, entre 1993 y 1999 el gasto social federal llegó a su nivel más elevado, tanto en volumen absoluto como en términos de gasto por habitante (gráficos 6 y 7).

Los avances en la educación, sobre todo en la enseñanza básica, significaron una transformación de gran alcance y profundidad: en 1999 el analfabetismo adulto había caído a $13.3 \%$ (gráfico 8) y la escolaridad había aumentado al $95.7 \%$ de los niños entre los 7 y los 14 años (gráfico 9) en la enseñanza básica y en la secundaria, cuya matrícula en seis años creció cerca de 68\%; disminuyeron la evasión y la tasa de repetición ,y hay un conjunto bastante grande de proyectos para retirar a los niños del trabajo y colocarlos a todos en la escuela. El programa Bolsa-Escola atenderá a diez millones de niños en el próximo año, lo que prácticamente abarcará a todos los niños de los

GRAFICO 6

Brasil: Gasto social federal, 1980-1999

(En miles de millones de reales de 1999)

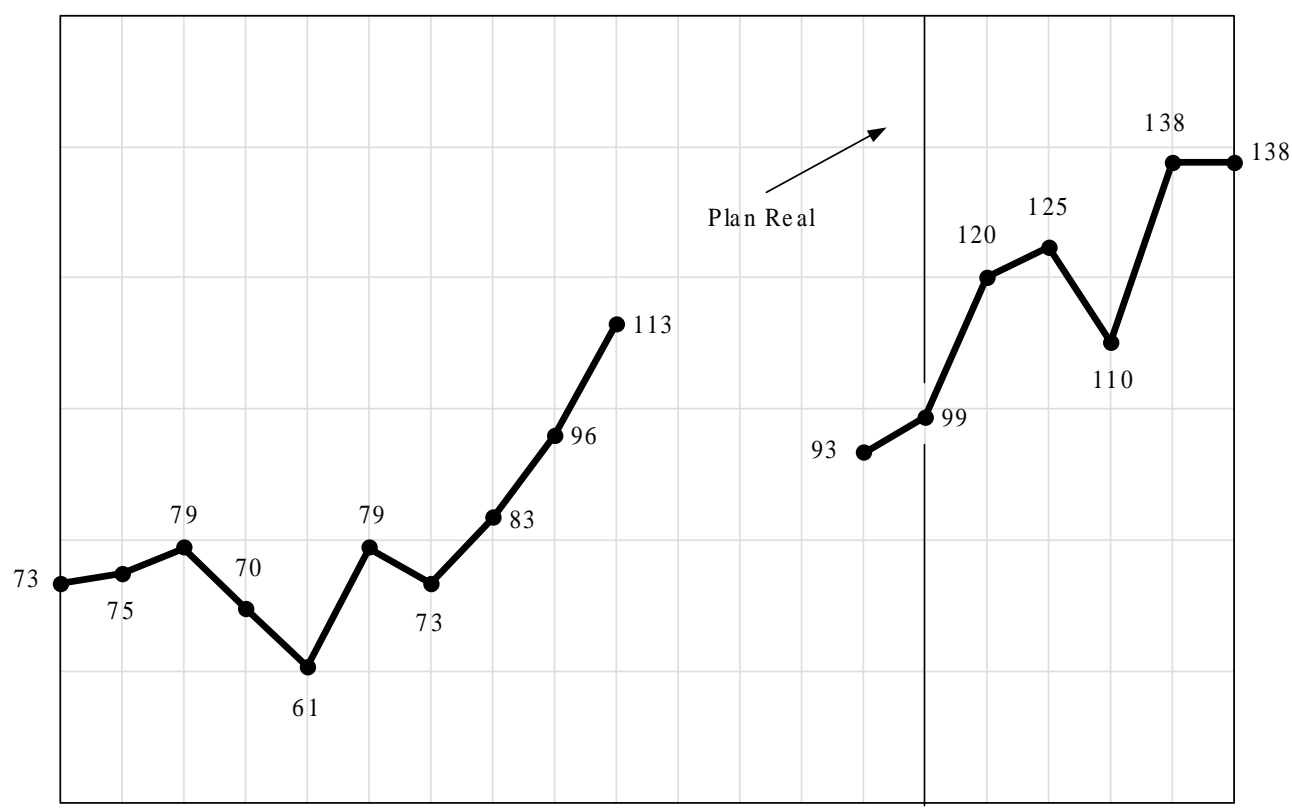

19801981198219831984198519861987198819891990199119921993199419951996199719981999

Fuente: IPEA/DISOC sobre la base de estadísticas mensuales de los sistemas SIAFI/SIDOR. 
GRAFICO 7

Brasil: Gasto social federal per cápita

(Promedios anuales por períodos en reales de 1999)

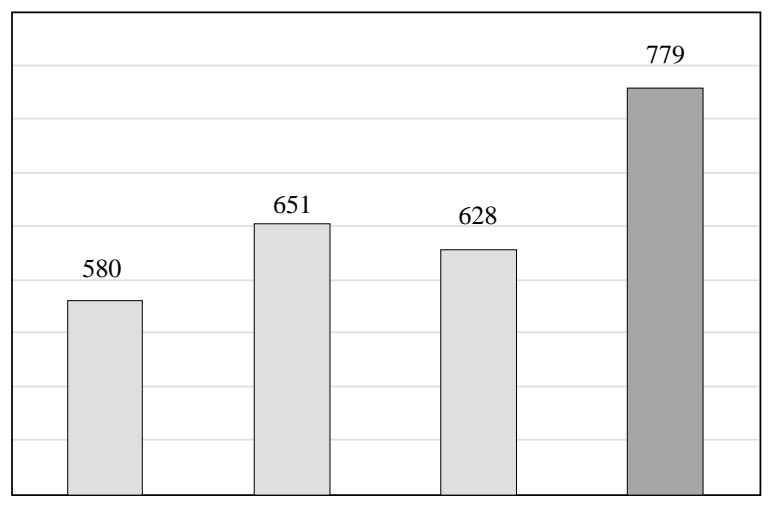

1980-1984

1985-1989

1993-1994

1995-1999

Fuente: IPEA/DISOC, sobre la base de estadísticas mensuales de los sistemas SIAFI/SIDOR.

GRAFICO 8

Brasil: Tasas de analfabetismo en la población de 15 años y más, 1983-1999

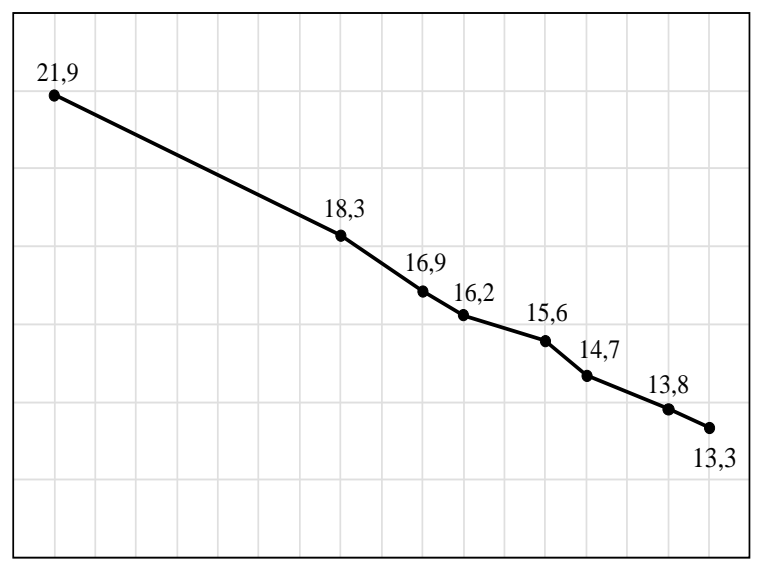

1982198319841985198619871988198919901991199219931994199519961997199819992000

Fuente: IPEA, sobre la base de encuestas de hogares del IBGE.

seis millones de familias más pobres (Brasil, Presidencia de la República, 2001).

En salud, el programa brasileño contra el SIDA se convirtió en un paradigma mundial. Se están introduciendo innovaciones importantes en materia de medicamentos, como el apoyo a los llamados medicamentos genéricos y la creación de una farmacia básica. El Programa de Médicos de Familia atiende hoy a 3230 municipios con una población estimada en 38 millones de personas. El Programa Agentes Comunitarios de Salud, complementario del anterior, cuenta con 144199 agentes en 4562 municipios y atiende a 82
GRAFICO 9

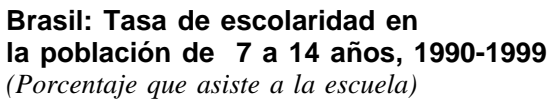

(Porcentaje que asiste a la escuela)

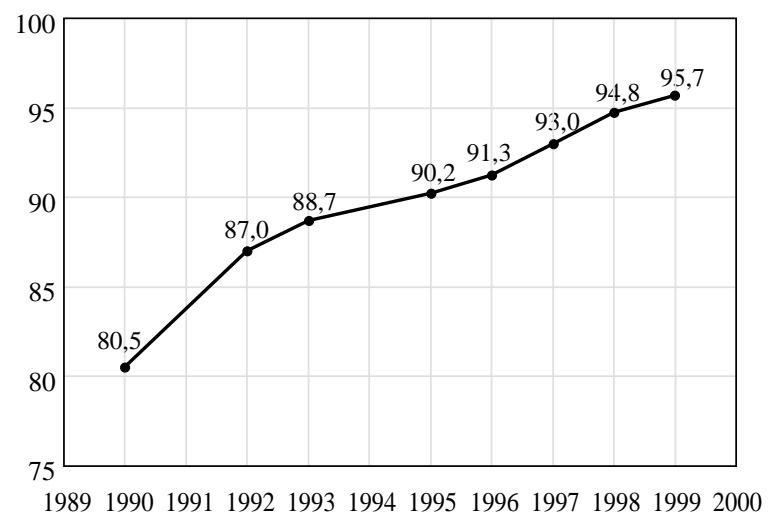

Fuente: IPEA, sobre la base de encuestas de hogares del IBGE.

GRAFICO 10

Brasil: Mortalidad infantil, 1990-2000

(Por mil nacidos vivos)

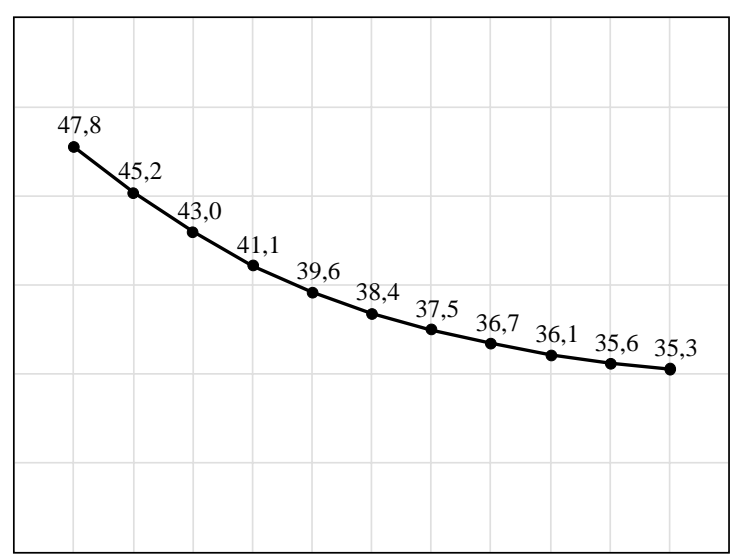

1989199019911992199319941995199619971998199920002001

Fuente: IBGE y Ministerio de Salud.

millones de personas. Las campañas nacionales de inmunización son permanentes y en el año 2000 la mortalidad infantil cayó a 35.3 por mil nacidos vivos (gráfico 10). El financiamiento federal para la salud se elevó de 14800 millones de reales en 1995 a 26000 millones en 2001.

En materia de reforma agraria, 465000 familias recibieron tierras en 1995, lo que representa el doble del total de familias que las recibió en los 30 años transcurridos entre 1964 y 1994. Casi 18 millones de hectáreas fueron expropiadas para la reforma agraria y 
en seis años se otorgaron más de 7000 millones de reales en créditos para la agricultura familiar (gráfico 11).

Los esfuerzos por erradicar el trabajo infantil iniciados en 1996 dieron buenos resultados, al garantizar la permanencia en la escuela de casi 400000 niños y adolescentes que antes trabajaban en actividades penosas o degradantes (gráfico 12).

En materia de trabajo, el programa de calificación profesional del trabajador (PLANFOR) contribuyó a aumentar las posibilidades de empleo y de ingreso, a elevar la productividad y la capacidad de competencia y a dar mayor estabilidad en el empleo. Entre 1995 y

GRAFICO 11

\section{Brasil: Asentamiento anual de familias sin tierra en 1995-2000 \\ (Total de familias asentadas)}

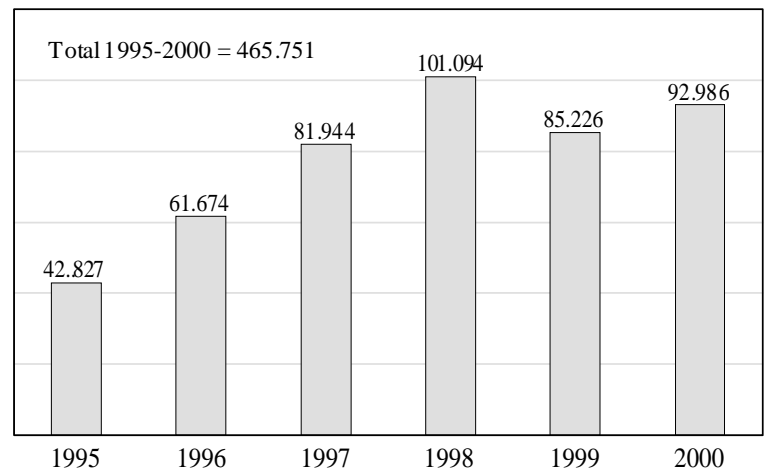

Fuente: Ministerio de Desarrollo Agrario.

GRAFICO 12

Brasil: Incidencia del trabajo infantil (grupo etario de 10 a 14 años), 1992-1999

(Porcentaje económicamente activo de este grupo)

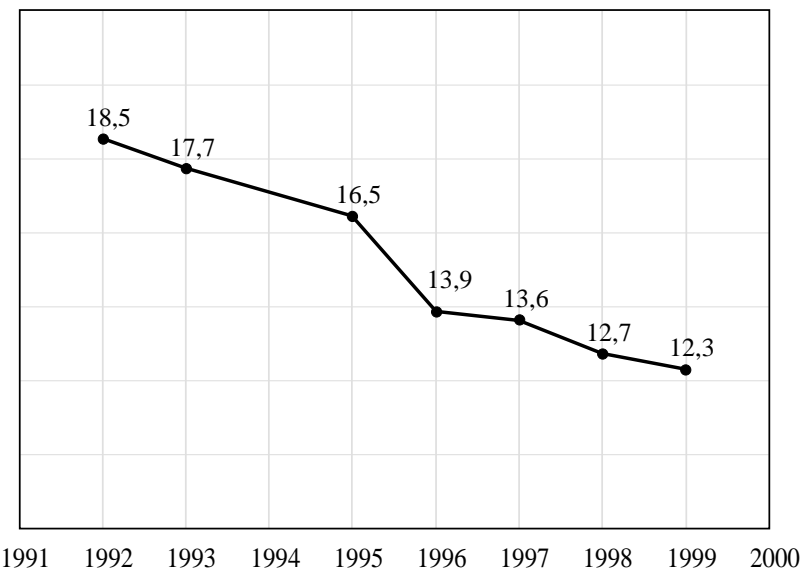

Fuente: IPEA, sobre la base de encuestas nacionales de hogares del IBGE.
2000, se capacitaron 11.3 millones de trabajadores, en el año 2000 más de 3 millones y en el año 2001 se habrían capacitado o recapacitado 4 millones más. Otra iniciativa importante fue el Programa de Generación de Empleo y Renta (PROGER urbano y rural), que da financiamiento para actividades de capacitación y de asistencia tecnológica a los trabajadores. Más de 1000 millones de reales se han aplicado anualmente a este programa (Cardoso, 2001).

En la transferencia directa de ingresos a personas y familias hubo significativos avances y los programas federales de este tipo (como el de jubilación rural, el de seguro contra el desempleo, los beneficios de LOAS, la Bolsa-Escola y la Bolsa-Alimentación) suman más de 20000 millones de reales por año.

Durante los siete años de vigencia del Plan Real, con sus diversas repercusiones, en el Brasil se redujo la proporción de pobres de $43.9 \%$ a $31.9 \%$ y la de indigentes de $19.5 \%$ a $14.5 \%$. Y todos los indicadores sociales, excepto los de desempleo y subempleo, registraron mejoras significativas.

Un indicador que representa el aumento del poder de compra resultante de la caída de la inflación es el acceso a bienes de consumo duraderos. Entre 1992 y 1999, el porcentaje de domicilios que tenían televisión aumentó de $73.4 \%$ a $87.8 \%$; el acceso a refrigeradores se elevó de $70.2 \%$ a $82.8 \%$ de los domicilios y el de teléfonos de $17.5 \%$ a $37.6 \%$ (gráfico 13 ).

Incluso la desigualdad del ingreso, recalcitrante por más de treinta años y que permanece elevadísima, exhibió una pequeña reducción.

GRAFICO 13

Acceso a bienes duraderos, 1992-1999

(Porcentaje de los hogares que los poseen)

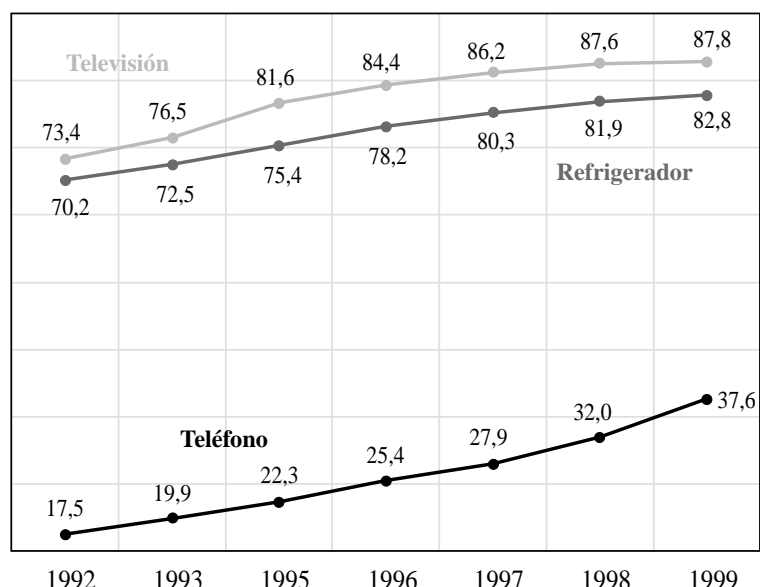

Fuente: IPEA, sobre la base de encuestas nacionales de hogares del IBGE. 
En tercer lugar, cabe mencionar que estos resultados, por objetivos e importantes que sean, no tranquilizan a la opinión pública brasileña y menos aun a la oposición. La cuestión social sigue siendo el punto focal de descontento e insatisfacción de grandes segmentos de la población.

Particularmente significativa en este sentido es la evaluación hecha por determinados segmentos de la clase media brasileña, sobre todo los que dependen del Estado y que se beneficiaban del padrón corporativo de política social que predominaba en el pasado. Estos se encuentran muy insatisfechos y hay claros indicios de que su calidad de vida no se benefició de las reformas en la misma medida que los demás sectores. Desarrollar actividades de protección social para estos segmentos se ha convertido en un desafío creciente, en vista de la competencia agudizada, los cambios en los requisitos profesionales y la mayor inseguridad que caracterizan hoy al mundo del trabajo y a la vida urbana.

Esta descompaginación entre la evolución objetiva de los indicadores sociales y la percepción que parte de la población tiene de su situación, junto con lo mucho que queda por hacer en el área social del Brasil, hacen obligatorios nuevos avances en el campo de las políticas sociales. Resulta pues imperativo, frente a las restricciones presupuestarias y a los límites impuestos por la necesidad de garantizar el equilibrio fiscal y macroeconómico, examinar nuevos y más eficaces mecanismos de articulación y coordinación.

\section{Bibliografía}

Amadeo, E. y otros (2000): Orçamento social da União, Brasilia, Secretaría de Política Económica, Ministerio de Hacienda del Brasil.

Arretche, M. y V. Rodríguez (orgs.) (1999): Descentralização das políticas sociais no Brasil, São Paulo, Fundaçao de Amparo à pesquisa do Estado de São Paulo (FAPESP)/Instituto de Investigación Económica Aplicada (IPEA).

Baumann, R. (1999): O Brasil nos anos 1990: uma economia em transição, Brasil: uma década em transição, Rio de Janeiro, Campus.

Brasil, Presidencia de la República (1996): Uma estratégia de desenvolvimento social, Brasilia. (2001): Agenda de Governo: biênio 2001-2002, Brasilia.

Cardoso, F. H. (1994): Mãos à obra Brasil. Proposta de Governo, Brasilia.

(1998): Avança Brasil: mais 4 anos de desenvolvimento para todos. Proposta de Governo, Brasilia.

(2001): Mensagem ao Congresso Nacional: abertura da $3^{\circ}$ Sessão legislativa ordinária da $51^{\circ}$ legislatura, Brasilia, Secretaría de Comunicación, Presidencia de la República.

Draibe, S., M. H. Guimarães de Castro y B. Azeredo (1995): The System of Social Protection in Brazil, Democracy and social policy series, Working paper, $\mathrm{N}^{\circ} 3$, Notre Dame, Indiana, University of Notre Dame, The Helen Kellogg Institute for International Studies.

Faria, V. E. (1986): Mudanças na composição do emprego e na estrutura de ocupações, E. Bacha y H. Klein (eds.), A transição incompleta: Brasil desde 1945, Rio de Janeiro, Paz e Terra. (1991a): A montanha e a pedra: os limites da política social brasileira e os problemas de infância e de juventude, A. Fausto y R. Cervini (orgs.), O trabalho e a rua: crianças e adolescentes no Brasil urbano dos anos 80, São Paulo, Fondo de las Naciones Unidas para la Infancia (UNICEF)/Facultad Latinoamericana de Ciencias Sociales (FLACSO).

(1991b): Cinquenta anos de urbanização no Brasil, Novos estudos CEBRAP, № 29, São Paulo, Centro Brasileño de Análisis y Planeamiento, marzo.
(1994): The Current Social Situation in Brazil: Dilemmas and Perspectives, Democracy and social policy series, Working paper, $\mathrm{N}^{\circ} 1$, Notre Dame, Indiana, University of Notre Dame, The Helen Kellogg Institute for International Studies.

(1999): La política social en Brasil: una mirada comparativa, J. Carpio e I. Novacovsky (comps.), De igual a igual: el desafio del Estado ante los nuevos problemas sociales, Buenos Aires, Fondo de Cultura Económica/Sistema de Información, Monitoreo y Evaluación de Programas Sociales (SIEMPRO)/ Facultad Latinoamericana de Ciencias Sociales (FLACSO)

(2000): Brasil: compatibilidade entre a establização e o resgate da dívida social, Pobreza e política social, Cadernos Adenauer, $N^{\circ} 1$, São Paulo, Fundación Konrad Adenauer.

(2001): A política social no Brasil: uma perspectiva comparada, A. Vogel y S. C. Yannoulas (coords.), Políticas públicas de trabalho e renda e controle democrático: a qualificação dos conselheiros estaduais de trabalho no Brasil, São Paulo, Universidade Estadual Paulista Julio de Mesquita Filho (UNESP).

Faria, V. E. y M. H. Guimarães de Castro (1989): Política social e consolidação democrática no Brasil, en Alexandrina Sobreira de Moura (ed.), O Estado e as políticas públicas na transição democrática, São Paulo, Brasil, Editora Revista dos Tribunais, LTD.

Faria, V. E. y E. Graeff (2000): Preparando o Brasil para o século XXI: uma experiência de governo para a mudança, en Vilmar Faria y Eduardo Graeff (comps.), Globalização e governo progressista: novos caminhos, Reunião de Florença, 1999, Brasilia, Instituto Teotônio Vilela.

Giambiagi, F. y M. M. Moreira (1999): A economia brasileira nos anos 90, Rio de Janeiro, Banco Nacional de Desarrollo Económico y Social.

Henriques, R. (org.) (2000): Desigualdade e pobreza no Brasil, Rio de Janeiro, Instituto de Investigación Económica Aplicada (IPEA). 